\title{
Poesía
}

\section{Pierre Ronsard}

Trad. Carlos Clementson, Córdoba, UCOPress, 2017, 2 vols., 985 pp.

\section{José Reyes de LA Rosa \\ Universidad de Córdoba}

La traducción poética constituye una actividad literaria tan necesaria como polémica y controvertida. Necesaria, por cuanto que la historia de la poesía universal no hubiera sido lo que es y ha significado en el mundo de la cultura sin la constante labor traductora a lo largo de los siglos. Pero discutida y aun denostada también, por la dificultad que entraña trasladar sin menoscabo a otra lengua una forma de expresión caracterizada, tradicionalmente, desde el punto de vista formal, por la utilización de elementos de tan difícil aclimatación como el verso y la rima, y, fundamentalmente, por el valor connotativo de su lenguaje y la función estético-simbólica de su discurso.

El resultado es un debate secular e interminable donde se afrontan posiciones tan extremas como las que niegan toda posibilidad de traducir poesía (Georges Mounin, Les problèmes théoriques de la traduction, Paris, Gallimard, 1963) y aquellas que admiten la viabilidad de traducir cualquier texto poético (Octavio Paz, Traducción literaria y literalidad, Barcelona, Tusquets 1971). Entre estas dos posiciones han transitado la teoría y la práctica traductora de las últimas centurias, que no ha cejado en su esfuerzo de encontrar procedimientos adecuados para una traducción poética que no sea "une traduction poudre aux yeux", Henri Meschonnic, Poétique du traduire, Lagrasse, Verdier 1999, p. 281). Una traducción, pues, que no enturbie la vista, de la que nos da Octavio Paz (op. cit., p. 23) la clave rememorando a Paul Valéry: "el ideal de traducción poética consiste en producir con medios diferentes efectos análogos". Esos efectos tienen, sin duda, mucho que ver con la reproducción de la musicalidad y el ritmo del poema, que para Teodoro Sáez Hermosilla es el ideal al que 
debe tender toda traducción poética. Para este traductólogo, que piensa que la poesía no se identifica forzosamente ni con el verso ni con la métrica, el ritmo es "una estructuración específica del sentido con todos los aspectos que conlleva: lengua, cultura, significación, estilo, metro, fonética y simbolismo" (El sentido de la traducción, reflexión y crítica, León, Universidad de León, 1994, p. 44).

En cualquier caso, la traducción de un poema ha de ser, sin más remedio, otro poema que reproduzca, a ser posible, todos los elementos de la expresión poética. Para ello, las prácticas traductivas utilizadas pueden ir desde las propuestas de los llamados "traductores modernistas" (Jonathan Baillehache: "L'OULIPO et la traduction moderniste", Formules, 16, 2012), con Ezra Pound a la cabeza, que preconizaban la recreación total del poema, hasta la traducción creativa como forma de "metamorfosis cultural", que propugna el poeta traductor Ángel Crespo ("El tiempo en la palabra. Una poética de la metamorfosis cultural”, Anthropos, 97, 1989, p. 29), pasando por las fórmulas de manipulación y transformación textual, que utilizan los traductores del OULIPO (Atlas de Littérature Potentielle, Paris, Gallimard, 1981), conducentes a diferentes formas de reescritura. En todas estas prácticas de la traducción poética la mediación intercultural se revela como un instrumento primordial de la actividad traductora, que hace del traductor un auténtico "pasador" de la cultura, porque, como señala Solange Hibbs, refiriéndose a la traducción en general,

incluso en los dominios más alejados de la literatura, el texto para traducir, el discurso para comprender, y el mensaje para restituir llevan las marcas de su enraizamiento en una cultura de origen más o menos diferente de la cultura receptora. Uno de los desafíos para el traductor estriba en su papel de mediador en la comunicación intercultural que subyace en toda traducción ("La traduction au XXI" Siècle: pratiques et défis", en Études et Travaux de l'école doctorale, $\mathrm{n}^{\circ} 1$, Toulouse, Université de Toulouse Le Mirail, 2003, p. 9; traducción nuestra).

Este papel esencial del traductor, como puente entre culturas que a través de un cuidadoso trabajo de mediación creadora aclimata con suma destreza el verso de otra lengua y cultura en la suya propia, es el que 
desempeña magistralmente el poeta y traductor Carlos Clementson en su monumental traducción de la poesía de Pierre de Ronsard.

Se trata de un ambicioso trabajo que constituye no solo la mayor empresa traductora a la lengua espańola de la obra del gran poeta renacentista francés, sino también uno de los estudios introductorios a la vida y la obra del autor galo más completos y reveladores de cuantos se han hecho en el ámbito hispánico. Las casi mil páginas que componen esta obra revelan el triple y concienzudo trabajo de Clementson como historiador incisivo de un periodo crucial de la historia de Francia, como avezado crítico literario del Renacimiento francés y como feliz traductor de una poesía que marcó, sin duda, un momento decisivo en la letras galas y europeas.

Editada en dos volúmenes por UCOPress, la editorial de la Universidad de Córdoba, con impresión y maquetación muy cuidadas, la obra ha sido galardonada como "mejor traducción" en los XXI Premios Nacionales de Edición Universitaria (UNE) de 2017, que distinguen a las mejores obras publicadas por las universidades y los centros de investigación.

La edición de Carlos Clementson recoge doscientos poemas traducidos, la más rica y variada antología del poeta francés hasta ahora publicada en Espańa, acompańados de un "Estudio introductorio" y un apéndice de "Notas y comentarios", sumando un total de 985 páginas. En el "Estudio introductorio", de 142 páginas, Clementson nos acerca a la vida y la obra de Pierre de Ronsard a través de una cronología biográfica y bibliográfica y de un análisis crítico-literario que sitúa al poeta en el contexto político y cultural de la Francia convulsa y refinada del siglo XVI, en el que transcurriría toda la vida de Ronsard (1524-1585), convirtiéndose en un testigo de excepción que se erige, al igual que siglos más tarde Víctor Hugo, en el "eco sonoro de su tiempo".

Los terribles avatares de la dinastía de los Valois, próxima a su desaparición, las Guerras de Religión que durante cuarenta años de ese siglo ensangrentaron a Francia, y la tensión permanente con España, el vecino rival y gran enemigo, marcarán conjuntamente la vida y la obra de Ronsard, el autor más completo y prestigioso de su tiempo en el país vecino: "poeta polifónico, poseedor de un magistral instrumento de muchas cuerdas", nos dice Clementson, que se refiere a las ocho terribles guerras de religión para afirmar que, "paradójicamente, propiciaron otra 
de las grandes creaciones engagées del genio ronsardiano, las cuales, siglos después, sirvieron de ilustre precedente inspirador a la gran musa satírica, comprometida y combativa, de Victor Hugo" (p. 140). Un minucioso trabajo, pues, historiográfico y de crítica literaria, exento de vana erudición, que nos conduce de manera fácil y amena a través de los hechos más relevantes que marcaron la vida de una corte turbulenta y elegante, donde Ronsard reina como poeta, y que tiene en el Valle del Loira, en los suntuosos castillos y jardines renacentistas, el paisaje inspirador de los mejores versos de su poesía.

Así, transitando por este edénico decorado, Clementson nos acerca a la obra del poeta de la Pléiade para determinar su personalidad artística y su carácter desde la función que ejerce la naturaleza en su creación. Un fino análisis literario de la presencia y el valor del entorno se inicia con este párrafo revelador:

Pocos paisajes están tan telúrica y espiritualmente fundidos en la memoria del lector a unos determinados objetos artísticos y literarios como la poesía de la Pléiade a los horizontes y castillos palaciegos del valle del Loira. Son su hábitat, a la vez, tanto cultural como natural. Se trata de una poesía que ha nacido de esta tierra fecunda, grávida y elegante, llena de riqueza, de serenidad, de equilibrio, antes que la tenebrosa llamarada de la discordia civil encendiera el genocidio ideológico de las guerras de religión, y el delicado epicureísmo de Ronsard y sus susurros de amor se convirtieran en el terrible alarido de Les Tragiques de D’Aubigné (p. 43).

Descubrimos de esta manera, de la mano de Clementson, al poeta renacentista impregnado de esa naturaleza amable y risueńa para expresar y exaltar "la feliz correspondencia de los castillos y la naturaleza del gran río con la fina corriente de humanismo y poesía, también de epicureísmo y alegría de vivir, generados en su seno" (p. 44).

Bajo el epígrafe de "El huerto de Ronsard", Clementson nos ofrece una amplia mirada a toda su producción poética, una de las más fecundas de la literatura francesa, con más de ochenta mil versos, pero también de las más desconocidas en España. Y en ello estriba uno de los grandes méritos de Clementson, que viene a sumarse al de traductor del clásico francés: el de darnos a conocer esta obra inmensa del "humanista apasionado 
y ferviente estudioso de la Antigüedad" que es Pierre de Ronsard. Porque más allá de algunos sonetos de fama universal, como el que comienza "Quand vous serez bien vieille, au soir a la chandelle", o de la delicada oda "Mignone, allons voir si la rose...", que, nos recuerda Clementson, leíamos en los manuales de literatura francesa de nuestro antiguo bachiller — cuando el francés era la única lengua extranjera que se estudiaba en España-, poco más hemos conocido de una obra que compendia y representa como ninguna otra el espíritu humanista y los logros literarios del Renacimiento galo.

En la antología de Carlos Clementson descubrimos al poeta imitador de los clásicos greco-latinos y al seguidor de la tradición italiano-petrarquista, que introduce y reinventa en su idioma composiciones poéticas como la oda, el himno o la égloga, de inspiración pindárica, anacreóntica u horaciana. Descubrimos también al poeta introductor de nuevos ritmos y estrofas y al gran renovador de la lengua francesa, creador de numerosos neologismos y cultismos que ilustran y modernizan el francés de su tiempo. Son todas ellas innovaciones que tendrán una gran repercusión en la lengua y la literatura francesas de los siglos posteriores. Pero descubrimos, sobre todo, al gran poeta del amor, al poeta sonetista de Los Amores de Casandra, de María, de Los sonetos para Helena, que hacen de Ronsard, según Clementson,

uno de los más libérrimos cantores de la pasión amorosa, sobre todo de la pasión francamente erótica, aunque nunca despojada de una cierta ternura, con una fina capacidad de penetración psicológica en los cambiantes entramados de las relaciones sentimentales, al tiempo dotado de una muy espontánea y original expresividad en el tratamiento del amor (p. 62).

Pero no sólo conocemos al Ronsard hedonista, al epicúreo cantor de los placeres de la vida, del carpe diem horaciano, que nos aconseja, como Garcilaso o Góngora en España, "Cueillez des aujourd'hui les roses de la vie". En su poliédrica obra admiramos también una poesía meditativa y filosófica a base de himnos (de la eternidad, de la muerte...), discursos y amonestaciones (de las calamidades de estos tiempos, sobre conflictos civiles y religiosos), y de elegías y epitafios. Todas estas composiciones, la mayoría de grandes dimensiones, son, especialmente los discursos, en 
palabras de Clementson, "un modelo de dicción grave, austera, dolorida, cargada de sinceridad y sentimiento, en los que el lenguaje poético, a veces, se aproxima vívidamente al tono de la lengua hablada, de manera conmovedora y actualísima, en especial en el dicterio y la ironía, o en la confesión personal (p. 63)

Esta poesía, poco o nada traducida y comentada en el ámbito hispánico, se nos muestra ahora $y$, antes de ser traducida, se analiza, para su mejor comprensión y disfrute, de manera muy didáctica, ofreciéndonos, al final de la obra, 73 páginas de "Notas y comentarios" de inestimable valor documental y literario. Cabe destacar en este apartado la amplia y precisa información sobre topónimos de la geografía ronsardiana, sobre la identidad de numerosos personajes presentes en los poemas, sus referentes y filiaciones y el propio proceso de creación. Resultan también particularmente útiles y pedagógicos los comentarios y explicaciones relativos a la mitología, tan abundante en toda la obra del poeta renacentista. Junto con el prólogo, se convierten en un verdadero ensayo de crítica literaria y en una utilísima guía de la cultura francesa del siglo XVI, de excepcional importancia para una lectura concienzuda y placentera de la extraordinaria antología que nos ofrece el investigador y poeta traductor.

Siguiendo la estela de otros grandes vates, Carlos Clementson se ha sentido desde siempre atraído por la traducción de poesía, que ha discurrido pareja a su propia creación. Con versiones de poesía catalana, gallega, portuguesa e inglesa, pero sobre todo francesa, el propio traductor se refiere a su antología de Ronsard señalando que se trata de la culminación de un proyecto y de un meticuloso trabajo iniciado hace más de tres décadas. Entre tanto, su interés por el Renacimiento francés le había llevado ya a traducir, en 1991, Les Regrets, la obra más conocida de Du Bellay, el poeta amigo y compañero de Ronsard en la Pléiade, que Clementson titula en castellano Lamentos y añoranzas. Una magnífica traducción en verso que, para Alicia Piquer Desvaux ("Traducción y recepción de Ronsard y otros poetas de su tiempo", en Los clásicos franceses en la España del siglo $X X$ : estudios de traducción y recepción, coords. Francisco Lafarga y Antonio Domínguez, Barcelona, PPU, pp. 57-66), es la que "mejor logra recrear la cadencia y el ritmo original", superando con creces otras traducciones existentes. Pero no sólo el Renacimiento ha centrado la actividad traductora de Clementson: una amplísima antología de la poesía francesa, desde 
la Edad Media hasta nuestros días, se halla en estos momentos próxima a su publicación. Una apasionante labor concretada, por el momento, con esta extensa antología de Ronsard, donde se confirma la calidad que ya demostrara en su traducción de la otra gran figura de la Pléiade.

Respecto a la recepción de Ronsard en España, conviene señalar que ha estado marcada, como bien señala Clementson, en primer lugar, por la rivalidad que enfrentó a las monarquías francesa y española durante los siglos XVI y XVII, afectando lógicamente a las relaciones culturales entre ambos países; y asimismo, por el olvido en el que cayó la obra del poeta en Francia a lo largo de más de dos siglos, tras las duras críticas y la condena que sufrió por parte del clasicismo, hasta su recuperación, ya en el siglo XIX, por el crítico romántico Sainte-Beuve y poetas como Nerval y los parnasianos. Pero no es totalmente cierto que en España, a diferencia de otros países europeos donde se admiró al poeta francés ya en su tiempo, se ignorara totalmente a Ronsard. Como ha demostrado precisamente Piquer Desvaux (op. cit., p. 58).

\begin{abstract}
paradójicamente, los grandes poetas espańoles del Siglo de Oro conocen y admiran a sus coetáneos franceses, lo que a menudo es silenciado por los estudiosos de hoy en día de la poesía española, atentos casi exclusivamente a describir la influencia ciertamente indiscutible de Italia y los clásicos de la Antigüedad, cuando el contacto por razones históricas de las literaturas española y francesa era y es innegable.
\end{abstract}

La investigadora cita a Lope como gran admirador de Ronsard, al que considera "célebre" y "felicísimo poeta", y se refiere a la dedicatoria del Fénix en su comedia El verdadero amante, donde afirma que "solo surge un poeta nacional en cada siglo, y con suerte, como el Petrarca en Italia, el Ronsardo en Francia y Garcilaso en España” (ibidem).

En su estudio, Piquer Desvaux analiza la presencia en nuestro país no solo de Ronsard sino de otros poetas de su tiempo (Du Bellay, Louise Labé, Agrippe d'Aubigné...), rastreando las traducciones a lo largo del siglo XX. Respecto a Ronsard, se refiere a la antología de Fernando Maristany, Antología general de poetas franceses (s.f., entre 1920 y 1922), donde aparecen seis poemas traducidos. Luego tendremos que trasladarnos hasta la segunda mitad del siglo XX para encontrar en castellano una versión 
completa de los Sonetos para Helena, en 1982, debida a Carlos Pujol. La edición bilingüe de Pujol se aleja bastante, según Piquer Desvaux (op. cit., p. 62), de la sonoridad ronsardiana y está concebida "como simple apoyo al lector que puede leer la obra en su versión original”. Una crítica, pensamos, demasiado rigurosa, que no hace justicia con el traductor catalán y que no tiene en cuenta la antología aparecida en el 2000 (Pierre de Ronsard, Poesía, trad. Carlos Pujol, Valencia, Pre-Textos), cuya calidad, como señala con acierto Luis Antonio de Villena en El Cultural (17 de mayo de 2000), es innegable.

En la antología bilingüe de Carlos Clementson la traducción no está, en ningún caso, concebida como mero apoyo al lector, sino que se revela como ese puente que nos permite apreciar de qué manera la sonoridad y el ritmo ronsardianos encuentran el eco perfecto de su cadencia en el molde castellano. Porque la traducción de Clementson responde perfectamente a unos postulados argumentados de manera reiterada por el propio poeta traductor, que se pueden resumir en su concepto de traducción creadora o de "transcreación". La idea se fundamenta en la visión de Ángel Crespo acerca de la traducción como un auténtico género literario, con palabras recogidas por el propio Clementson (op. cit., p. 17): "El traductor, al recrear en su lengua los aspectos formales, semánticos y filológicos de la obra traducida, está haciendo, en realidad, una obra personal, y, en consecuencia, original". Una obra original que, de acuerdo con los traductores oulipianos, revela la potencialidad creativa de la actividad traductora. Ahora bien, para conseguir esa originalidad de la traducción creadora, el traductor ha de tener una determinada actitud y cumplir una serie de exigencias, como nos señala el poeta traductor: "Para traducir creadoramente a un autor, primero hay que comulgar con él, participar en cierta medida de su particular mundo espiritual o expresivo, sentirse vinculado o sintonizar de algún modo, con el latido estético o la palpitación cordial de su poesía" ("Prólogo" a Víctor Hugo, Poesía, trad. Rafael García de Mesa, Córdoba, Universidad de Córdoba, 2002, p. 20). Y esa participación en el mundo espiritual de Ronsard la podemos apreciar en la acertada elección de los poemas que se traducen en la antología, con todos los registros de la poesía ronsardiana, en doce apartados con títulos tan significativos como: "Bajo el signo de Píndaro", "Las rosas de la vida", "El poder de los mitos", "La Arcadia cortesana" o "La rosa y la espada". Cada uno de esos 
capítulos recopila, siguiendo el proceso creativo de Ronsard, los poemas que Clementson ha elegido de acuerdo únicamente con criterios estéticos y de interés literario, desechando de su antología lo que él considera "pesados artefactos laudatorios, de hinchazón retórica, cuajados de eruditas alusiones mitológicas y empedrados cultismos", composiciones que, según el antólogo, para el lector moderno "apenas si mantienen algún vigor literario, y menos aún cierta emoción poética” (p. 70).

Tratando, no obstante, de dar a los lectores el Ronsard más completo y representativo de su genio creativo y de la estética renacentista, la antología depara, junto a los 109 sonetos de los Amores y otros recueils, otras composiciones tan específicas de aquel momento literario como las odas, églogas, estancias, himnos, madrigales, canciones y elegías, a las que se ańaden discursos y epitafios, para reunir dos centenares de poemas que suman más de nueve mil versos. La oferta se muestra capaz de satisfacer el gusto más exigente de los amantes de la poesía y de la traducción, porque las versiones en castellano pueden leerse como auténticos poemas originales, gracias a una transposición, auténticamente creadora, donde el ritmo y la musicalidad del verso originario circulan en la lengua espańola moldeada y modulada con gran acierto creativo, para que el verso ronsardiano discurra en ella fluido y vigoroso, sin asperezas, y pueda cantar en castellano la misma melodía.

De su quehacer traductivo nos da cuentas el propio Clementson precisando los criterios que han regido su trabajo y que coinciden con esa labor mediadora del traductor:

Hemos intentado, pues, acercarnos a los equivalentes sincrónicos formales seguidos por la poesía que por aquellas mismas fechas se cultivara en España bajo idénticos o parecidos magisterios espirituales o estilísticos, marcadamente renacentistas e italianos. Es decir, trasvasar de un orden lingüístico a otro unas experiencias literarias y humanas, comunes a la mayor parte de la Europa de su tiempo, buscando una expresión histórica paralela en castellano que, por otro lado, tampoco fuese disonante con la lengua literaria actual (p. 157).

Así pues, guiado por una concepción del traductor como intermediario cultural y, al mismo tiempo, creador, Clementson aclimata la métrica ronsardiana del alejandrino, del decasílabo y otros metros menores con ajustada adecuación en el molde castellano, consiguiendo mantener la 
musicalidad, el ritmo y la cadencia del verso original en recreaciones llenas de belleza y sensualidad, como en estos versos octosílabos de la oda VII del Libro Segundo:

Mi dama no brinda besos

sino tal suerte de encantos

que son del alma sustento

y alimento de los dioses, [...];

o en esta recreación en endecasílabos del soneto XLII de los Amores a Casandra:

Claveles y azucenas combinados no igualan lo purpúreo de su rostro, ni el oro fino excede a sus cabellos, ya anden ellos trenzados o bien sueltos.

Del coral curvilíneo de sus labios nace una dulce risa que me encanta, y envidiosa la tierra que ella pisa un prado en flor esmalta entre sus plantas.

De ámbar y almizcle está su boca llena. ¿Qué más diré? Que he visto la llanura - tonante el aire y roto en cien lugaressu mansa frente, reina entre los dioses, refrenarle su diestra al mismo Júpiter $\mathrm{y}$ rendirse a sus ojos todo el cielo.

Pero podemos también apreciar la majestuosa sonoridad del clásico alejandrino francés, en el molde español de catorce sílabas, en estos primeros versos de la égloga primera:

Las umbrosas encinas, que sin arte Natura por las altas florestas al azar alimenta, al pastor son más frescas y al rebaño más dulces que las plantas injertas hábilmente en los huertos.

En cuanto al debatido asunto de la rima, Clementson no la rehuye de manera absoluta en su traducción, aunque, como es lógico suponer en 
una antología de estas proporciones, suele verter los metros ronsardianos en versos blancos. Así pues, no rechaza la rima fortuita e incluso la busca, permitiéndose una recreación bastante feliz de algunos sonetos en perfecta rima consonante. Su reescritura corrobora la idea oulipiana de potencialidad creativa, como en el logrado ejemplo de soneto traducido en el inusual verso dodecasílabo español y rima consonante:

Un diferente y amoroso torpor sin que madure en mi alma verdea de mis dos ojos una fontana ondea y un Mongibelo da a mi pecho su ardor.

Del uno el fuego y del otro el licor ora me hiela, ora ya me flamea; y así en mí el uno contra el otro guerrea sin que uno quede del otro vencedor.

Amor, que triunfe uno u otro te ruego, sea el hielo frío o el ardoroso fuego, y que uno u otro concluya este debate.

Amor, que ganas tengo ya de morir. Mas dos venenos no ahogan nunca el vivir, en tanto el uno contra el otro combate.

Para concluir, conviene subrayar que la mayoría de los doscientos poemas que nos ofrece esta antología no han sido nunca traducidos en español. Así, más de cuatro siglos después, los lectores pueden leer en castellano esta inmensa obra del poeta francés, que nos abre un anchuroso ventanal a la esplendorosa poesía del Renacimiento europeo. Los versos en español que leemos en esta antología forman parte de ese patrimonio cultural común que ahora podemos apreciar como auténticos poemas españoles, aunque fueran escritos por Ronsard, en francés, hace más de cuatrocientos años.

El libro de Clementson viene a colmar así un injusto vacio y a reparar el desdén manifestado secularmente por los traductores de poesía en España hacia esta figura emblemática de las letras galas. Es de agradecer, pues, en este siglo ya definitivamente posmoderno, la aparición de una antología que invita a visitar el fecundo huerto de Ronsard y a recoger, sin esperar a mañana, las rosas de la vida. 